\title{
PAISAGISMO E EDUCAÇÃO AMBIENTAL: REVITALIZAÇÃO DO ESPAÇO ESCOLAR E SUAS POTENCIALIDADES PROBLEMATIZADORAS
}

Deisi Geneci Sander ${ }^{1}$

Resumo: O presente artigo apresenta a reflexão sobre a aplicação de uma oficina pedagógica sob o viés da Educação Ambiental (EA) e da Ecopedagogia em duas escolas municipais de ensino fundamental em São Leopoldo/RS, que desejavam a revitalização paisagística do espaço escolar e de uma pracinha no entorno da escola. O projeto de ação foi idealizado a partir do Curso de especialização Lato Sensu em Educação Ambiental da Universidade Federal do Rio Grande (UAB/FURG), tendo como objetivo oferecer subsídios formativos aos educadores das escolas à incorporação da dimensão socioambiental na revitalização paisagística dos espaços, explorando noções de interdisciplinaridade, meio ambiente, Educação Ambiental e Ecopedagogia. Para isso, pesquisou-se as concepções dessas categorias nos textos de Marcos Reigota, Carlos Frederico Bernardo Loureiro, Isabel Cristina de Moura Carvalho e Moacir Gadotti. Por meio da aplicação de questionários e oficinas, foi possível concluir que a maioria dos educadores mantém uma concepção naturalista de meio ambiente, apesar de a concepção de Educação Ambiental aproximar-se significativamente dos seis objetivos da EA definidos da Carta de Belgrado. A aplicação da oficina resultou, de acordo com as respostas dos docentes, na ampliação do entendimento das concepções das categorias mencionadas, na concordância de possível reformulação da prática pedagógica para atender ao que prima a Ecopedagogia e na compreensão do rico campo pedagógico que pode ser explorado com os alunos, durante a revitalização dos espaços públicos citados.

Palavras-chave: Prática Pedagógica; Meio Ambiente; Educação Ambiental; Ecopedagogia.

1 Universidade Federal de Rio Grande - FUR. E-mail: deisisanders@gmail.com 


\section{Introdução}

Este artigo refere-se a um projeto de ação executado nas escolas EMEF Arthur Ostermann e EMEF Tancredo Neves, por meio do Centro Permanente de Educação Ambiental (CEPEA) e pelo Jardim Botânico, ambos vinculados à Secretaria Municipal de Meio Ambiente (SEMMAM), e situados na Unidade de Conservação de Proteção Integral denominada Parque Natural Municipal Banhado da Imperatriz, em São Leopoldo/RS. Por ser estagiária do curso Técnico em Paisagismo no Jardim Botânico do município, fui convidada a participar de reuniões nas escolas mencionadas acima, porque ambas desejavam revitalizar dois espaços públicos; a primeira, o espaço escolar; a segunda, uma pracinha próxima à escola.

Em conversa inicial com as diretoras, percebi que ambas não estavam levando em consideração o rico campo pedagógico que poderia ser explorado com os alunos ao revitalizar espaços usados por eles e pelos demais da comunidade escolar. Diante desse contexto e compreendendo que espaços públicos são ponto de encontro que possibilita/possibilitaria ação política, onde as relações, tensões, cultura, relação com a Natureza se manifestam e que, por isso, podem ser considerados o termômetro dos dilemas sociais, como seu próprio abandono pelas autoridades, julguei pertinente aliar minhas atividades como estagiária em Técnico em Paisagismo e como aluna da Especialização em Educação Ambiental (FURG). Com o presente intuito, pesquisei e formulei oficina pedagógica para os professores dessas escolas, no âmbito da Educação Ambiental, a fim de problematizar e qualificar ações que pudessem voltar-se ao objetivo primeiro da escola, o de educar.

Assim, o objetivo geral da ação aplicada foi oferecer subsídios formativos aos educadores das EMEF Arthur Ostermann e EMEF Tancredo Neves à incorporação da dimensão ambiental, com o oferecimento de duas oficinas, que exploraram categorias, como interdisciplinaridade, meio ambiente, Educação Ambiental, Ecopedagogia na tentativa de responder, junto com os educadores, a seguinte questão: de quais maneiras o desejo de revitalizar o espaço escolar e do seu entorno pode favorecer à convergência de múltiplos campos de saberes de modo a contribuir à discussão socioambiental e à mudança de postura dos cidadãos envolvidos?

Com base nessa reflexão, foram sugeridas atividades que englobassem as diferentes áreas do conhecimento, de maneira interdisciplinar. Este artigo, entretanto, não traz o resultado pós oficina, isto é, não verifica se os educadores adotaram ou não as sugestões das ações pedagógicas, por questão de tempo para a finalização desta escrita. Tais propostas pedagógicas ficaram no campo da possibilidade de enfrentamento de problemas locais, como o diagnóstico do que a comunidade quer para seu espaço e a análise dessa situação, para partir ao planejamento, ao trabalho em equipe, à organização e à tomada de decisões, estimulando a colaboração entre professores, a participação dos alunos e da comunidade ao que tange 0 espaço público que frequentam.

revista brasileira educação ambiental 
O referencial teórico selecionado para embasar o presente artigo e ação aplicada perpassa por José Ávila Aguiar Coimbra, Cláudia da Silva Cousin, Francisco Gutièrrez e Cruz Prado, Philippe Pomier Layrargues, Willian da Silva Medeiros e Vantoir Roberto Brancher e Marcos Reigota. Além destes, foi dado ênfase nas leituras sobre a Ecopedagogia, proposta por Moacir Gadotti.

Resumidamente, a ação iniciou-se com pesquisa de opinião à direção, professores e alunos da EMEF Arthur Ostermann sobre o que querem para o espaço escolar, e à comunidade escolar da EMEF Tancredo Neves (direção, professores, alunos, pais e/ou responsáveis) sobre o que querem para o espaço da pracinha, próxima da escola. Com a tabulação dos dados, elaborei graficamente dois projetos paisagísticos e fiz pesquisa bibliográfica para elaboração da oficina. Assim, o presente artigo traz a investigação das concepções de meio ambiente e Educação Ambiental entre os docentes que atuam nessas escolas e a reflexão acerca das propostas pedagógicas oferecidas a eles, convergindo com o que trazem os autores pesquisados.

\section{Concepções de Meio Ambiente, de Educação Ambiental e da ecopedagogia}

Com base no Art. 225 da Constituição Federal, no qual todos têm direito ao meio ambiente ecologicamente equilibrado, bem de uso comum do povo e essencial à sadia qualidade de vida, impondo-se ao Poder Público e à coletividade o dever de defendê-lo e preservá-lo para as presentes e futuras gerações, entende-se Educação Ambiental como um processo permanente no qual os indivíduos e a comunidade tomam consciência do meio ambiente através de conhecimentos, adquirindo valores, habilidades, experiências e engajamento a fim de resolverem problemas ambientais e sociais. Para isso, entretanto, é necessária a criação de contextos de aprendizagem em Educação Ambiental a fim de transformá-los. A questão "transformação" traz à superfície a complexidade do fazer a Educação Ambiental, pois é preciso averiguar como ela se insere: se na reprodução da sociedade contemporânea ou na busca de novos patamares societários. Para evidenciar essa questão, Loureiro (2004) chama atenção para o fato de que:

A ideia de que "tudo é válido" desde que se almeje proteger o ambiente, ignorando o modo como este se constitui, não colabora para alcançarmos novas relações sociais e formas sensoriais e perceptivas de nos compreendermos e nos sentirmos como parte da sociedade e de uma vida planetária (LOUREIRO, 2004, p. 22).

A questão problematizadora que o autor coloca é a mesma defendida pelo educador Paulo Freire: não há como mudar a realidade (problemas ambientais, exploração humana, desigualdades) se continuarmos com a educação que reproduz a sociedade capitalista, se continuarmos com a 
"educação bancária", como Freire (1997) a chamava. Por isso, o caminho teórico percorrido no projeto aplicado procurou discutir alguns fundamentos da Educação Ambiental crítica, sem, com isso, torná-la como única que solucionará os problemas socioambientais globais.

Escolhidas as vertentes dessa perspectiva pedagógica, é preciso explicitar a concepção de Educação Ambiental adotada. Carvalho (2004) critica o fato de que, de tempos em tempos, retornam argumentos que levam ao entendimento de que Educação Ambiental é simplesmente educação, desconsiderando a construção de anos de incorporação da especificidade do ambiental na prática educativa na formação dos sujeitos contemporâneos. Segundo sustenta a autora:

(...) Educação Ambiental acrescenta uma especificidade: compreender as relações sociedade-natureza e intervir sobre os problemas e conflitos ambientais. Neste sentido, o projeto político-pedagógico de uma Educação Ambiental Crítica seria o de contribuir para uma mudança de valores e atitudes, contribuindo para a formação de um sujeito ecológico (CARVALHO, 2004, p. 18).

Esse sujeito ecológico é orientado a práticas de solidariedade com o meio social e ambiental, o que contribui, coletivamente, na identificação, problematização e ação perante as questões socioambientais. Essa construção é possível se esse sujeito entende o meio ambiente como o definido por Reigota:

(...) um lugar determinado e/ou percebido onde estão em relações dinâmicas e em constante interação os aspectos naturais e sociais. Essas relações acarretam processos de criação cultural e tecnológica e processos históricos de transformação da natureza e da sociedade (REIGOTA, 2006, p. 21).

Essa compreensão possibilita ampliar a participação política dos cidadãos, consolidando os princípios democráticos e buscando soluções para os problemas socioambientais, a fim de alcançar qualidade de vida para todos. A Educação Ambiental, porém, não deve ser vista de forma que há uma minoria consciente e que esta deva conscientizar a maioria, colocando em segundo plano a construção histórica e cultural desta; educar ambientalmente é propiciar o diálogo com o outro, contribuindo a um processo de conscientização por meio da ação com conhecimento e com o outro.

Dito isso, o método interdisciplinar foi o mais estudado (COUSIN, 2004), pois ele proporciona compreensão global sobre o que se estuda e 
problematiza, e a troca de experiência entre professores e alunos e o envolvimento da comunidade escolar. Esse e os outros enfoques colaboram para que a comunidade estabeleça relação entre degradação/abandono do meio ambiente e de espaços públicos às práticas e agentes sociais específicos (ACSELRAD, 1992; SERPA, 2014). Alcançada essa relação, chegamos mais próximo ao que propõe a Educação Ambiental Crítica, pois:

Ao ressignificar o cuidado para com a natureza e para com o Outro humano como valores ético políticos, a Educação Ambiental crítica afirma uma ética ambiental, balizadora das decisões sociais e reorientadora dos estilos de vida coletivos e individuais (CARVALHO, 2004, p. 19).

Tratando-se do aspecto "ação" utilizado no projeto, é preciso explicitar o enfoque dado a ele sob a perspectiva da Ecopedagogia, que tanto pode ser entendida como movimento pedagógico quanto como uma abordagem curricular (GADOTTI, 1993). De acordo com o autor:

A Sociedade Civil vem assumindo a sua cota de responsabilidade diante da degradação do meio ambiente percebendo que apenas através uma ação integrada é que essa degradação pode ser combatida. Os movimentos sociais e populares e as Organizações Não-Governamentais têm alertado os governos e a própria sociedade sobre os danos causados ao meio ambiente e aos seres humanos por políticas públicas anti-sustentáveis (GADOTTI, 1993, p. 04).

Essa responsabilidade corresponde ao entendimento da Ecopedagogia como movimento pedagógico. Já, quanto a uma abordagem curricular vem como aquela que implica:

(...) uma reorientação dos currículos para que incorpore certos princípios defendidos por ela. Estes princípios deveriam, por exemplo, nortear a concepção dos conteúdos e a elaboração dos livros didáticos. Piaget nos ensinou que os currículos devem contemplar o que é significativo para o aluno. Sabemos que isso é correto, mas incompleto (GADOTTI, 1993, p. 05). 
pensar sobre a formação inicial e continuada dos professores. Diante de qualquer proposta que tem como objetivo o de inovar o ensino, torna-se imprescindível renovações das práticas educativas, alcançadas principalmente com a formação continuada. A preocupação com a formação dos docentes nesse eixo temático fez com que a Política Nacional de Educação Ambiental (PNEA - Lei № 9.795/99) criasse seu órgão gestor (Decreto № 4.281/02) integrado pelo Ministério do Meio Ambiente e Ministério da Educação, a fim de encontrar caminhos que consolidassem o propósito no país. Em 2004, após ampla consulta pública, criou o Programa Nacional de Educação Ambiental (ProNEA), trazendo a Resolução do CNE no 2, de 15 de junho de 2012, que estabelece as Diretrizes Curriculares Nacionais para a Educação Ambiental (2005, p. 48-45). Nessa Resolução, o Capítulo II - Objetivos da Educação Ambiental traz, em seu artigo 14, o que as instituições de ensino devem contemplar:

I - abordagem curricular que enfatize a natureza como fonte de vida e relacione a dimensão ambiental à justiça social, aos direitos humanos, à saúde, ao trabalho, ao consumo, à pluralidade étnica, racial, de gênero, de diversidade sexual, e à superação do racismo e de todas as formas de discriminação e injustiça social (2005, p. 51).

Esse recorte converge com os princípios da Ecopedagogia, que deve ser entendida como um movimento social e político, em que a Educação Ambiental é um pressuposto. $O$ fato de a oficina priorizar ações no meio onde vivem os cidadãos envolvidos, não significa que as questões aparentemente distantes do seu cotidiano não devam ser abordadas, pois o que propõe a Ecopedagogia é a tomada de consciência não só como cidadão local mas também do como cidadão planetário.

\section{Os primeiros passos para o caminho existir}

Como mencionado na introdução, o projeto englobou inicialmente a aplicação de pesquisa de opinião à comunidade escolar Arthur Ostermann (direção, professores, alunos) e à comunidade escolar Tancredo Neves (direção, professores, alunos, pais e/ou responsáveis) sobre o que queriam para o espaço público escolar e para a pracinha, próxima à Tancredo Neves. Após esse levantamento, tabulou-se os dados a fim de verificar os desejos e necessidades para esses espaços públicos, a partir dos quais os projetos paisagísticos foram elaborados e representados graficamente a cada escola.

De posse desses projetos paisagísticos, foi proposta oficina com atividades que contemplassem a interdisciplinaridade em torno do tema Meio Ambiente, de acordo com a proposta Ecopegagógica, aos educadores das 
duas escolas, totalizando 33 professores das EMEF Arthur Ostermann e EMEF Tancredo Neves, durante as reuniões pedagógicas deles, que ocorrem uma vez por mês.

De maneira geral, a oficina propôs: a leitura do livro "Manual do Defensor do Planeta", de João Alegria e Rodrigo Medeiros, por se tratar de obra que contempla a temática de maneira ampla sobre o tema e por ter como destinatários alunos com os quais as escolas trabalham. A escolha justificou-se também porque contempla o currículo Ecopedagógico, uma vez que envolve a consciência planetária. Dada a apresentação do livro, sugestões de atividades foram elaboradas a partir dele e voltadas aos componentes curriculares Português, Arte, Ciências, Geografia e História, sob a ótica do campo socioambiental. Isso sempre relacionando com os espaços a serem revitalizados. Essas sugestões não se encerraram em si, pois a ideia foi deixar a construção de um plano pedagógico aberto a novas sugestões dos educadores durante as oficinas (no plural pois são duas escolas).

\section{Caminho construído, passos mais detalhados}

As escolas municipais de São Leopoldo reúnem-se coletivamente para discutir questões pedagógicas e firmar acordos uma vez por mês, com duração de 3 horas. No dia 23 de outubro de 2017, a EMEF Tancredo Neves cedeu 1h30min do tempo de sua reunião pedagógica, e a EMEF Arthur Ostermann cedeu 1h50min, no dia 08 de novembro de 2017.

A fala inicial foi a apresentação e o esclarecimento do objetivo da oficina. A música "Tudo muda", disponível no site da RGE Sul2, na seção Educacional, tocava enquanto fotocópias com duas perguntas iam sendo distribuídas: 1. 0 que é meio ambiente para ti? 2. O que entende por Educação Ambiental?

Assim que os professores responderam, os papéis foram recolhidos, a música recebeu pausa e a apresentação iniciou, mostrando o projeto paisagístico. Apresentaram-se imagens das plantas, pensadas para eles a fim de que pudessem ter ideia do valor estético de cada uma na composição do espaço, com valorização das nativas, na tentativa de ressignificar a importância da característica local. Após, mostrou-se uma foto do planeta terra, justificando, a todos, a escolha devido à capacidade humana em avançar tecnologicamente para a descoberta do cosmos. Em seguida, apresentou-se a definição de meio ambiente por Reigota, a qual já transcrevemos anteriormente.

Com base nessa definição, destacou-se a importância das relações constantes entre os aspectos naturais e sociais, isto é, o homem como natureza que a transforma culturalmente. Deu-se ênfase de que meio ambiente é o resultado não só da relação entre humano $\mathrm{x}$ natureza, mas também da relação entre humano $x$ humano. Com isso, assevera-se que a importância de

2Disponível em <http://www.rgesuleducacional.com.br/\#materiais $>$ 
definirmos antes o que entendemos por meio ambiente para que possamos definir que Educação Ambiental queremos proporcionar. Como sustentação a essa proposição, as palavras de Reigota são evidenciadas:

\begin{abstract}
Educação Ambiental, como perspectiva educativa, deve analisar temas que permitem enfocar as relações entre a humanidade e o meio natural, e as relações sociais sem deixar de lado suas especificidades. Preocupa-se em abordar aspectos políticos, econômicos, culturais e sociais (REIGOTA, 2006, p. 25).
\end{abstract}

Após esse entendimento, imagens que ilustram a problemática atual dessas relações foram mostradas, como a desigualdade social, a exploração de recursos naturais de forma insustentável e o reverso disso: a luta pela sustentabilidade também travada pela sociedade. Adiante, apresentou-se, de modo geral, a Ecopedagogia e seus precursores.

A Ecopedagogia engloba todo e qualquer comportamento do ser humano na e com a Terra. E a educação que se preocupa primeiramente com a ética, que prima pela construção do ser humano cidadão, antes mesmo do ser humano cientista. Em relação ao currículo, segundo Gadotti (1993), preocupa-se com a elaboração de conteúdos significativos para o aluno por serem significativos à saúde do planeta.

Francisco Gutiérrez e Cruz Prado (1999), também desbravadores da Ecopedagogia, asseveram que os grandes problemas socioambientais, como a pobreza, o aquecimento global, a poluição das águas e do ar, os resíduos tóxicos, e as armas de destruição em massa podem atingir pessoas de todas as regiões do planeta. Dessa forma, abordou-se a cidadania planetária pois acredita-se que a Educação Ambiental não está vinculada à transmissão do conhecimento sobre a natureza, e sim à possibilidade de ampliar a participação política dos cidadãos envolvidos. Quando alguma atividade específica da EA é pensada, não se pode deixar de mencionar seu lado social, econômico e político.

Dada essa apresentação, enfatizou-se suas características [Ecopedagogia]: não há dissociação entre cidadania e ecologia, nem antagonismo entre as dimensões local e global; entende a interdependência, a interconexão e a luta comum para todas as formas de vida (rede); o sentido das nossas vidas não está separado do sentido do próprio planeta; é democrática e solidária. Na tentativa de exemplificar esse entendimento por artistas consagrados, trechos do poema VII, de Alberto Caeiro (heterônimo de Fernando Pessoa), um poema de Carlos Drummond de Andrade e um trecho da música "Janela para o mundo", de Milton Nascimento foram mostrados.

Apresentou-se brevemente a interdisciplinaridade em EA com seleção do que disse Genebaldo Freire Dias: "pela própria natureza do ambiente, dadas 
as suas múltiplas interações de fundo ecológico, político, social, econômico, ético, cultural, científico e tecnológico, não se poderia tratar o assunto em uma única disciplina" (2003, p. 117). Por isso, a interdisciplinaridade corresponde ao que propõe uma Educação Ambiental comprometida com a transformação da realidade.

Depois desses breves embasamentos teóricos, distribuiu-se um mapa conceitual com sugestões de conteúdos e atividades pedagógicas, que poderiam ser disponibilizadas aos alunos de forma interdisciplinar. Esse mapa apresentou algumas sugestões apenas, porque o objetivo, a partir desse ponto da oficina, era de os professores continuarem com as intervenções didáticas interdisciplinares de maneira espontânea ao longo da apresentação dos próximos slides.

Antes de seguir com a apresentação, mostrou-se uma imagem que corresponde às correntes marítimas, com o propósito de resgatar o conteúdo para relacioná-lo com o vídeo "llha de Plástico - a morte dos oceanos", na tentativa de fazer com que os professores compreendessem que o estudo dos fenômenos naturais deve ser assimilado pelo aluno a ponto de ele poder refletir sobre sua ação no mundo. Dito de outra forma, o vídeo mostra o caminho que o lixo, em especial o plástico, faz quando é jogado no chão, mostrando o resultado negativo dessa prática, uma vez que interfere na vida de animais a quilômetros de distância, matando-os.

Percebeu-se que os professores ficaram chocados com as cenas, e comentaram que 0 vídeo pode ser uma atividade importante de conscientização da ação antrópica no planeta. Uma professora questionou com os colegas se seria adequado passar aos alunos, sendo eles tão novos. Em resposta, alguns disseram que o impacto era necessário, levando em consideração a importância da informação e do objetivo pedagógico.

A sequência dos próximos slides correspondeu às diversas atividades selecionadas para sugerir aos educadores. Em seguida, foram sugeridos três títulos de livros com a temática política e ambiental, adaptado à linguagem infantil: "A primavera da Lagarta", de Ruth Rocha, "A democracia pode ser assim", de Equipo Plantel e "Manual do Defensor do Planeta", de João Alegria e Rodrigo Medeiros. A fim de exemplificar a abordagem ambiental e política de um deles, selecionou-se imagens do último livro mencionado, apresentando os problemas que o narrador-personagem enfrentava ao longo da narrativa, bem como suas reflexões sobre eles. Ao final da oficina, ele foi disponibilizado integralmente em arquivo pdf.

Feito isso, apresentou-se o site Instituto Sociedade, População e Natureza ${ }^{4}$, uma vez que oferece um guia de elaboração de pequenos projetos socioambientais para organizações de base comunitária. Com ele, os

${ }^{3}$ Disponível em <https://www.youtube.com/watch?v=jK2lbhMrVaQ>.

${ }^{4}$ Disponível em <http://www.ispn.org.br/>.

Revbea, São Paulo, V. 14, № 4: 260-275, 2019. 
educadores podem ler projetos realizados e encontrar subsídios para escrevem os seus, de acordo com os objetivos da comunidade escolar.

Quanto a recursos financeiros para a execução do projeto de revitalização, tanto da pracinha do lado da EMEF Tancredo Neves quanto para o espaço escolar da EMEF Arthur Ostermann, uma lista de ações foi sugerida para angariar verba, como "financiamento coletivo"; "deixe seu troco à praça"; "bingo"; "rifar uma torta"; "Instituição privada"; "meio frango"; "setor privado"; "setor público"; "ação entre amigos com prêmios em dinheiro". Essas sugestões foram dadas, uma vez que ambas escolas adiantaram não ter verba para execução dos projetos paisagísticos, e pelo município em questão também asseverar que não dispõe de recursos. Os educadores julgaram viável algumas ações, as quais poderiam ser postas em prática no próximo ano letivo.

Como finalização da oficina, apresentou-se parte do último episódio do documentário "Cosmos"5 (entre os 34 e 37 minutos), apresentado pelo cientista Neil deGrasse Tyson, com texto do cientista Carl Sagan. Depois do vídeo, distribuiu-se outra folha com as seguintes perguntas: Sua visão sobre meio ambiente e Educação Ambiental foi ampliada? A Ecopedagogia pode ser estruturada na escola? A mostragem das respostas de todas as perguntas será dada no item que segue.

\section{Reflexões sobre a caminhada}

Reigota afirma que "para que possamos realizar a Educação Ambiental, é necessário, antes de mais nada, conhecermos as concepções de meio ambiente das pessoas envolvidas na atividade" (2006, p. 21). Por isso, foi feita a pergunta "O que é meio ambiente para ti?", cujas respostas foram distribuídas nas três representações dessa categoria, trazidas por Reigota (2007): naturalista, que prioriza aspectos naturais (flora, fauna), concebe visão física e biológica da natureza; antropocêntrica, que mantém uma relação com a natureza de forma que esta está para servir ao homem (natureza = recursos); e globalizante, visão que compreende a relação sociedade e natureza, o ser humano como parte do meio, incluindo, assim, aspectos políticos, econômicos e culturais. A Tabela 1, a seguir, apresenta os resultados, em percentuais, das respostas dos docentes, classificadas conforme as três representações citadas acima. Destacou-se algumas respostas, identificadas por números, dadas pelos educadores, identificados por letras.

${ }^{5}$ Disponível na provedora global Netflix. 
Tabela 1: Classificação das respostas dos docentes nas três representações de meio ambiente de Reigota.

\begin{tabular}{|c|c|c|}
\hline Naturalista & Antropocêntrica & Globalizante \\
\hline $\begin{array}{l}\text { 76\% } \\
\text { A1 É tudo que tem ao nosso } \\
\text { redor, do céu até no meio da } \\
\text { terra, nas águas, no ar... } \\
\text { B2 Meio ambiente é o meio em } \\
\text { que vivemos com seres vivos e } \\
\text { não vivos. }\end{array}$ & $\begin{array}{l}12 \% \\
\text { C4 Meio ambiente é tudo que nos } \\
\text { cerca, tudo que a natureza nos } \\
\text { oferece para nossa existência. } \\
\text { Estamos conectados com este } \\
\text { todo o tempo. } \\
\text { D5 Meio ambiente é tudo que nos } \\
\text { cerca, tudo que a natureza nos } \\
\text { oferece para nossa existência. }\end{array}$ & $\begin{array}{l}\text { E6 Meio ambiente é o espaço } \\
\text { que nos cerca, natural e } \\
\text { transformado pelo ser humano } \\
\text { por suas decisões. } \\
\text { F7 Em primeiro momento é todo } \\
\text { o nosso planeta com sua fauna e } \\
\text { flora, mares, ar, terra, plantas, } \\
\text { animais. Porém podemos } \\
\text { considerar os espaços urbanos } \\
\text { também, casas, prédios como } \\
\text { meio ambiente, onde vivemos } \\
\text { culturalmente. }\end{array}$ \\
\hline
\end{tabular}

Fonte: Formulada pela autora.

Como é possível observar, a maior parte deles concebe a dimensão Meio Ambiente como um conjunto de elementos físico-biológicos; estes relacionados às diversas formas de vida, correspondendo, assim, ao meio natural, à espacialidade, aquilo que está ao redor, ao lugar que é habitado pelo ser humano.

Interessante observar que poucos professores colocam-se como natureza que dela sobrevive. Assim como podemos observar um número mínimo que amplia a concepção de meio ambiente em seus aspectos políticos, culturais e econômicos, o que prejudica a compreensão dos problemas ambientais, que são gerados por esses aspectos e, consequentemente, as formulações de soluções para tais problemas. Percebe-se nas respostas dos professores a ausência da relação clara entre as relações sociais que também fazem parte dos problemas ambientais. A dinâmica relação humano $x$ natureza é evidenciada com economia assim como a relação humano $x$ humano $x$ natureza que compõem o pressuposto de como lidam com o Natural. Sobre isso, Cláudia da Silva Cousin levanta a questão de que:

(...) o modelo capitalista hegemônico fragilizou as relações dos seres humanos entre si e com o lugar ao qual pertencem. Ou seja, produziu assim o desenraizamento que conduz a não responsabilidade individual e coletiva, por deslocar os seres humanos de suas referências culturais e de sua identidade (COUSIN, 2010, p. 02). 
Esse recorte do texto de Cousin reforça a ideia de que é preciso problematizar o modo como a sociedade se organiza, e os efeitos dela sobre as relações humanas e sobre as tomadas de decisões quanto à exploração dos recursos oferecidos pelo planeta. É importante enfatizar que elas (as relações) não se dão fora do espaço, do ambiente onde se realizam e que, por isso, estão ligadas a ele.

Ainda, sobre a compreensão dos sistemas de vida (físico, biológico e social) que caracterizam o planeta Terra, com similaridades e diferenças, Genebaldo Freire Dias assevera:

A EA enfatiza as regularidades, enquanto mantém respeito pelos diferentes ecossistemas e culturas humanas na Terra. $\mathrm{O}$ dever de reconhecer as similaridades globais, enquanto se interage efetivamente com as especificidades locais, é resumido no lema da EA: "Pense globalmente, aja localmente" (Think globally, act locally) (DIAS, 2004, p. 224).

Esse lema deve ser permeado nas ações pedagógicas dos educadores, a fim de que os alunos e a comunidade local apreendam que todas as coisas estão conectadas por inter-relações, respeitando uma hierarquia. Entender de fato essas relações ajuda na atuação local.

Para analisar as respostas dadas à pergunta "O que compreende ser Educação Ambiental?", os seis objetivos da EA, definidos na carta de Belgrado e trazidos por REIGOTA (2006), foram utilizados:

1. Conscientização: mostrar-se sensíveis aos problemas ambientais regionais $\mathrm{e}$ globais;

2. Conhecimento: democratizar todo tipo de conhecimento a fim de que os cidadãos possam atuar diante dos problemas ambientais.

3. Comportamento: fazer com que os cidadãos, com a clareza dos valores sociais, atuem em prol dos problemas ambientais.

4. Competência: compreensão de que, para certos problemas ambientais, é preciso ajuda técnica.

5. Capacidade de Avaliação: capacidade dos cidadãos em compreender leituras, realizadas por técnicos especializados quanto a projetos de riscos ambientais.

6. Participação: responsabilidade dos cidadãos sobre os problemas ambientais de forma que atuem sobre eles com o objetivo de alcançar soluções.

Buscou-se palavras-chave nas respostas dos educadores que pudessem ser colocadas lado a lado com as dos objetivos da EA, definidos na carta de Belgrado, levando em consideração o número de vezes em que apareciam nas respostas (Tabela 2 ). 
Tabela 2: Seleção de palavras-chave nas respostas dos docentes, distribuídas conforme os objetivos da EA da carta de Belgrado.

\begin{tabular}{|l|l|}
\hline \multicolumn{2}{|c|}{ Subcategorias de Educação Ambiental sob a perspectiva dos objetivos } \\
\hline 1. Conscientização & $56 \%$ \\
\hline 2. Conhecimento & $56 \%$ \\
\hline 3. Comportamento & $76 \%$ \\
\hline 4. Competência & $25 \%$ \\
\hline 5. Capacidade de Avaliação & Não foi mencionado \\
\hline 6. Participação & $38 \%$ \\
\hline
\end{tabular}

Fonte: Produzida pela autora.

As respostas dadas pelos professores vão ao encontro das palavraschave dos objetivos definidos na carta de Belgrado, mesmo que não desenvolvidas de forma a aprofundar o entendimento de cada uma. Dito de outra maneira, se enfatizarmos o termo "conscientização", por exemplo, trazido pela maioria deles, não se sabe se as ações pedagógicas que proporcionariam essa consciência se dariam aos níveis regional e global. Por isso, a oficina trouxe essa reflexão: o quanto se trabalha para que os alunos alcancem o entendimento de que a preocupação com a questão ambiental deve ir além do espaço escolar, além do bairro, além da cidade deles.

Os termos "conhecimento" e "comportamento" também foram mencionados pela maioria dos professores presentes. Um é consequência do outro, pois é preciso primeiro entender o meio e os efeitos da atividade humana sobre ele para, depois, atuar diante dos problemas ambientais. Esta visão engloba o que Reed Noss, citado por Primack e Rodrigues (2001), figurou como a expansão da compreensão do indivíduo sobre todas as dimensões de sua vida, como "obrigações morais, saindo de si mesmo para incluir deveres com aqueles de sua família, do seu grupo social, de toda a humanidade, animais, todas as espécies, o ecossistema, e finalmente a Terra toda" (PRIMACK, RODRIGUES, 2001, p. 65).

Mesmo que a humanidade tenha avançado em termos de compreensão dos sistemas distintos de existência e dos efeitos da ação antrópica sobre o planeta, observou-se que o item "capacidade de avaliação" não foi encontrado entre as respostas dos professores. Isso se evidencia, muito provavelmente, pela própria fragilidade formativa deles e pelo fato de a formação à Educação Ambiental ainda estar mais presente no campo da pós-graduação (Müller Morales, 2009); e, quando oferecida, ainda apresentar estrutura baseada em aspectos mais filosóficos e de conhecimento geral da trajetória da EA do que propriamente técnico.

Quanto à formação, é importante trazer a problemática evidenciada por Layargues, em relação à contradição entre teoria e prática: 
na armadilha paradigmática da Educação Ambiental (GUIMARÃES, 2006), muitas vezes associada à modernização conservadora que ideologicamente captura intencionalidades políticopedagógicas manifestadas como críticas, mas contraditória e ingenuamente exercitando sua práxis de modo pragmático ou conservacionista; já na perspectiva da hegemonia do pragmatismo na Educação Ambiental Informal, essa crise de identidade seria mesmo intencional, pois se trata da voz ideológica dominante valendo-se do artifício da propaganda cultural para reproduzir seus valores e práticas (LAYARGUES, 2012, p. 398).

Isso significa dizer que a Educação Ambiental ainda enfrenta obstáculos para formar cidadãos com capacidade de incluir, nas suas leituras, a compreensão de fatores que englobem a ecologia, a política, a economia, o campo social e o estético. Além disso, ainda é difícil tornar o cidadão competente a codificar a linguagem técnica, usada em projetos de riscos ambientais, o que o torna vulnerável diante de pessoas que detêm tal conhecimento. Ainda, em especial sobre a formação dos profissionais de educação, Medeiros e Brancher (2016, p. 98), parafraseando Naná Mininni Medina, destacam que:

Um fator de dificuldade para a implantação de um processo de formação docente em Educação Ambiental é a maneira simplista com que esta tem sido concebida e aplicada, sendo reduzida a processos de sensibilização orientados por conteúdos das áreas das Ciências Naturais ou em atividades pontuais como o dia do meio ambiente, dia da água, dia do índio, dia da árvore.

Esse fato pode ser verificado nas respostas dadas pelos educadores das duas escolas e por ambas terem um professor responsável em abordar temas ambientais, realizar projetos, incluindo as datas comemorativas, citadas pelos autores, como mais uma matéria na organização curricular. Essa práxis dificulta a contemplação do último objetivo apontado na carta de Belgrado, a "participação", uma vez que os problemas ambientais não saem do campo da sensibilização; ação pedagógica importante, porém que não oferece todo aporte para uma prática atuante e transformadora socialmente.

Após a oficina foi conversado com os professores e solicitada uma avaliação. Os resultados seguem abaixo (Tabela 3 ):

Tabela 3: Avaliação dos professores sobre as categorias abordadas na oficina.

\begin{tabular}{|c|c|c|c|}
\hline \multicolumn{4}{|l|}{ Perguntas avaliativas entregues ao final da oficina } \\
\hline & $\operatorname{Sim}$ & Não & Talvez \\
\hline Sua visão sobre meio ambiente e Educação Ambiental foi ampliada? & $100 \%$ & & \\
\hline A Ecopedagogia pode ser estruturada na escola? & $97 \%$ & & $3 \%$ \\
\hline
\end{tabular}

Fonte: Elaborada pela autora. 
Conforme o resultado da avaliação, levando em consideração que a interdisciplinaridade faz parte dos princípios da Ecopedagogia e da Educação Ambiental, a oficina atingiu percentual significativo ao que se propunha. Obviamente que os desafios da aplicação na prática exigiriam retomada bibliográfica por parte dos docentes sobre as categorias abordadas no projeto. Apesar de elucidar as respostas dos professores sobre as categorias meio ambiente e Educação Ambiental, não foi o objetivo deste trabalho esgotar a análise dos discursos evidenciados nas respostas dos professores, mesmo porque, durante a oficina, não Ihes foi propiciado tempo hábil para refletirem mais detidamente sobre as perguntas feitas.

\section{Considerações finais}

As reflexões realizadas sobre as respostas dos professores procuraram trazer à luz a forma como os docentes entendem o meio ambiente e a Educação Ambiental de forma imediata, a fim de apresentar a linha ideológica que embasou a oficina. Essa oficina teve, como princípio metodológico, a ação interdisciplinar, vista como processo de conhecimento, durante a revitalização do espaço escolar e/ou de seu entorno. Ainda, todo o planejamento do trabalho procurou problematizar os consensos, construídos por grupos que têm influência na sociedade, para que o plano de ação pedagógico dessas escolas também sofresse reformulações; bem como para que compreendessem 0 trabalho conjunto e consciente sobre os fatores que levam a problemas ambientais, sem ingenuidades e para que não perdessem a oportunidade do rico campo pedagógico que se apresenta com o desejo de trabalhar com a terra, com o espaço vivido pela comunidade escolar.

Além disso, o trabalho se propôs a apresentar a Ecopedagogia no contexto do desejo de revitalização de espaços públicos (microcosmos), pois ela compreende a imbricada conexão planetária (macrocosmos). Assim, seja na criação de uma horta, seja na composição de um jardim e/ou área recreativa, é importante torná-los um campo pedagógico em que os alunos atuem diretamente, aprendendo valores em torno da vida, da morte, da solidariedade, da sobrevivência, da adaptação, da transformação, entre muitos outros.

$\mathrm{Na}$ busca por qualidade de vida para si, para o local, é imprescindível que se traga a discussão sobre a justiça também como um valor importante, uma vez que ela engloba o direito de todos a essa mesma tão almejada qualidade de vida; sem deixar de lado a problematização do que de fato é "qualidade de vida", de que maneira a nossa relação com a terra deve se dar para alcançarmos esse objetivo. 


\section{Referências}

ACSELRAD, H. Justiça Ambiental. In: FERRARO JUNIOR, L.A. (Org.) Encontro e caminhos: formação de educadoras(es) ambientais e coletivos educadores. Brasília: MMA. Diretoria de Educação Ambiental, 2005. p. 217 - 228.

AVANZI, M.R. Ecopedagogia. In: LAYRARGUES, P.P. (Org.) Identidades da Educação Ambiental Brasileira. Brasília: MMA, 2004. p. 35-49.

BRASIL. Constituição (1988). Constituição da República Federativa do Brasil. Brasília, DF: Senado Federal: Centro Gráfico, 1988. 292 p.

PATTO, M.H.S. (Org.) Introdução à Psicologia Escolar. São Paulo: Casa do Psicólogo,1997.

COIMBRA, J.A.A. Considerações sobre a interdisciplinaridade. In:_Interdisciplinaridade nas ciências ambientais. S.Paulo: Signus Editora, 2000, p.52-70.

COUSIN, C.S. Pertencimento Ambiental. Rio Grande: Universidade Federal do Rio Grande, FURG/SeaD, 2010, 10p.

DIAS, G.F. Educação Ambiental: princípios e práticas. São Paulo: Gaia, 2004.

GADOTTI, M. A ecopedagogia como processo apropriada ao processo da Carta Terra. Revista de educação pública, 2003. Disponível em: <http://www. ufmt.br/revista/arquivo/rev21/moacir gadotti.htm>. Acesso em 10 set. 2017.

GUTIÈRREZ, F.; PRADO, C. Ecopedagogia e cidadania planetária. São Paulo: Cortez/Instituto Paulo Freire, 1999.

LAYRARGUES, P.P. (coord.). Identidades da Educação Ambiental Brasileira. Brasília: Ministério do Meio Ambiente, 2004.

LAYRARGUES, P.P. Para onde vai a Educação Ambiental? O cenário político ideológico da Educação Ambiental brasileira e os desafios de uma agenda política crítica contrahegemônica. Revista Contemporânea de Educação. Brasília, n 14, p. 398-421. Ago/dez. 2012.

MEDEIROS, W.S.; BRANCHER, V.R. A concepção ambiental dos docentes de um curso técnico de um Instituto Federal de Educação no RS. Rev. Eletrônica Mestrado Educação Ambiental. v. 33, n.3, p. 92-109, set/dez. 2016.

MORALES, A.G.M. A formação dos profissionais educadores ambientais e a universidade: trajetórias dos cursos de especialização no contexto brasileiro. Educar, Editora UFPR, Curitiba, n. 34, p. 185-199, 2009.

PRIMACK, R.B.; RODRIGUES, E. Biologia da Conservação. Londrina: Gráfica Editora Midiograf, 2001.

REIGOTA, M. O que é Educação Ambiental? São Paulo: Brasiliense, 1994.

REIGOTA, M. Meio ambiente e representação social. 7. ed. São Paulo: Cortez, 2007.

SERPA, Â. O espaço público na cidade contemporânea. $2^{\text {a }}$ ed., São Paulo: Contexto, 2014. 